\title{
A review of the public-funded primary health care facilities for children in the pluralistic health care settings of Barbados, a Caribbean island
}

\section{Anders L. Nielsen and Alok Kumar}

Senior Lecturer, Faculty of Medical Sciences, The University of the West Indies, Cave Hill Campus, Barbados, West Indies

\begin{abstract}
Aim: The major objectives of this study were to evaluate the existing pediatrics health care service provisions and utilizations of the public polyclinics in Barbados. Furthermore, the aim was to assess if the existing manpower resources were adequate. Background: Barbados has a mixed health care system consisting of both a socialized and a private health care system. The Ministry of Health commissioned a needs assessment survey of the pediatrics primary health care at the public polyclinics. Methods: Primary data were collected through interviews with the public primary health care providers. Secondary data were collected from the Barbados Census Data and Ministry of Health statistics. Data were analyzed to assess the pediatrics primary health care service utilization and adequacy of existing resources at the polyclinics. Findings: In 2012, there were 62934 visits from children $<16$ years of age to the public polyclinics in Barbados and this accounted for $39.1 \%$ of all visits (both adults and children) to the polyclinics. An overall $16.7 \%$ of the visits were from children less than five years old to the Well Child Clinic for immunization and for growth and development monitoring; $32 \%$ of all physician consultations at the polyclinics were for children $<16$ years. Utilization of health services by children at the polyclinics was 5245 visits/month. Given an expected monthly demand for 10822 visits from children, the polyclinics serve $48.5 \%$ of the primary health care demand for children in Barbados. Conclusions: The public polyclinics play a pivotal role in the pluralistic primary health care system in Barbados. They fulfill nearly half of all the primary care demand and more importantly provides for almost the entire immunization demand, and thereby ensuring high coverage.

The existing resources, if used optimally, would reduce the long consultation time observed in this setting, and thereby increase the capacity considerably.
\end{abstract}

Key words: pediatrics health care service; provisions; public health care; utilizations Received 9 August 2014; revised 15 April 2015; accepted 3 May 2015; first published online 9 June 2015

\section{Introduction}

An accumulating literature documents the importance of a strong primary care infrastructure within

Correspondence to: Dr Anders L. Nielsen, 32 Stanford Road, Colchester, Essex, CO4 5NF England. Email: anders@ lassen-nielsen.com a health care system, especially in the context of the changing health care needs of children [Parchman and Culler, 1994; Shi, 1994; Starfield, 1994; Institute of Medicine (IOM), 2012]. Health care systems that are better organized around a primary care base achieve better health outcomes and greater population satisfaction at lower costs than health care systems more focused on specialty 
services (Starfield, 1994). In the United States, areas with more primary care physicians have lower rates of hospitalization for conditions that are sensitive to primary care interventions (Parchman and Culler, 1994) and lower infant mortality (Shi, 1994). A recent report by the IOM, USA, reinforces the importance of a strong primary care as a critical sector in the movement toward improved population health (IOM, 2012).

The most easterly island in the Caribbean, Barbados, is a small, densely populated, Englishspeaking country, with an estimated population of 287733 inhabitants living on $431 \mathrm{~km}^{2}$ (WHO, 2014). Its gross national income per capita is US $\$ 25670$ (2012 estimate) and its total expenditure on health as a percentage of gross domestic product stands at $6.3 \%$ (WHO, 2014). In 2011, Barbados was designated as a developed country by the United Nations Development Program (UNDP), and has a Human Development Index score of 0.776 (UNDP, 2014). Very recent estimates place life expectancy at birth as 75 years for males and 81 for females (WHO, 2014). The infant mortality rate is $10.93 / 1000$ live births (CIA, 2014) and mortality for children less than five years is 20/1000 live births for both sexes (WHO, 2014). Barbados also reports high immunization coverage rates $(\sim 90 \%)$ for children (UNICEF, 2013; WHO, 2014). Barbados has a mixed health care system consisting of both a socialized health care system and a private health care system. Public services are available across the primary-to-tertiary care spectrum for the entire population and are free of cost at the point of delivery. Pediatric public primary health care in Barbados is provided through eight primary health centers (the polyclinics) evenly spread over the country and two satellite health centers attached to two of the polyclinics. At present, there is no electronic health records in the public health care system. All patient records are handwritten and logs are manually kept/collected as well; thus, statistical data are manually collected and tabulated.

In this study, we critically examine the utilization and the available resources of the publicly funded pediatric primary health care. The study highlights the strengths and challenges of the public-funded health care provision that needs attention in order to further strengthen the public primary pediatric care in this country.

Primary Health Care Research \& Development 2016; 17: 157-165

\section{Methods}

The Ministry of Health, Government of Barbados commissioned a consultancy service to strengthen the pediatrics primary health care at its health centers - the polyclinics. A needs assessment survey of the polyclinics was undertaken. The major objectives of this needs assessment survey were to evaluate the existing health care service provisions and its utilization.

The following strategies were employed to conduct the needs assessment survey.

Assembling a project panel that comprised of a representative from the Ministry of Health, a Public Health Expert, a representative from the polyclinics, a representative from the University of the West Indies, which provides medical education in this country, a health care provider from the private sector and a representative from the secondary and tertiary health care provider.

The primary data collection for this research focused on the year 2012. A member of the research team visited all of the eight polyclinics and met individually as well as collectively with the staff at the polyclinics.

The primary data were collected from the Medical Officers of Health (MOHs) and from the senior public health nurses (SPHNs) paper records at each polyclinic (data shown in Tables 1-4).

In addition, a group interview with the medical staff using a semi-structured interview guide was conducted at each polyclinic. In total 48 physicians and 66 nurses participated. The interviews were guided by the following headings (Kumar and Nielsen, 2014).

Available resources consisting of physical resources/infrastructures, soft medical resources such as procedural manuals and guidelines, and professional development opportunities available.

Human resources available listed under the subheadings - physicians, nurses and ancillary medical support staff. Ancillary support staff includes nutritionists, medical social workers, councilors, child psychologists and rehabilitative service staff including occupational therapists, physiotherapists and speech therapists.

Available health care provisions consisting of preventative care provision and utilization, curative care provision including home visits and utilization, as well as rehabilitative care provisions. 
Table 1 Selected demographic and primary health care provider data for Barbados, 2012

\begin{tabular}{lll}
\hline Population demography & Inhabitants & \\
\hline $\begin{array}{l}\text { Total population } \\
\text { Population }<16 \text { years of age }\end{array}$ & 287733 & \\
\hline $\begin{array}{l}\text { Doctors providing primary care } \\
\text { to children }\end{array}$ & $\begin{array}{c}\text { Numbers } \\
\text { of doctors }\end{array}$ & $\begin{array}{c}\text { Full time } \\
\text { equivalent }\end{array}$ \\
\hline $\begin{array}{l}\text { Doctors providing primary care } \\
\text { to children (total) }\end{array}$ & 155 & 144 \\
$\begin{array}{l}\text { GP's in public sector at } \\
\text { polyclinics (full time) }\end{array}$ & 49 & 49 \\
$\begin{array}{l}\text { GP's in private sector (full time) } \\
\text { GP's in private sector (part time) }\end{array}$ & 77 & 77 \\
$\begin{array}{l}\text { Pediatricians in private sector } \\
\text { (full time) }\end{array}$ & 9 & 5 \\
$\begin{array}{l}\text { Pediatricians in private sector } \\
\text { (part time) }\end{array}$ & 9 & 9 \\
\hline $\begin{array}{l}\text { Primary care utilization in the } \\
\text { public sector }\end{array}$ & Numbers of visits \\
\hline $\begin{array}{l}\text { Visits to the under five Well Child } \\
\text { Clinic (nurse visits) (of these, }\end{array}$ & 26959 & \\
$\begin{array}{l}7014 \text { need GP consultation as } \\
\text { well) }\end{array}$ & & \\
$\begin{array}{l}\text { Visit to the GP unit (<5 children) } \\
\text { Visit to the GP unit (5-15 years) }\end{array}$ & 21408 & 14567 \\
$\begin{array}{l}\text { Total number of visits to } \\
\text { polyclinics (<16 children) }\end{array}$ & 62934 & \\
$\begin{array}{l}\text { Total number of visits to } \\
\text { polyclinics (adults) }\end{array}$ & 98160 & \\
$\begin{array}{l}\text { Total number of visits to } \\
\text { polyclinics (children + adults) }\end{array}$ & 161094 & \\
\hline & & \\
\hline & & \\
\hline
\end{tabular}

The answers were recorded in the interview sheets and subsequently categorized and tabulated.

Secondary data are defined as data previously collected or data that is routinely collected for other purposes. The secondary data section is comprised of demographic profile, health statistics, childhood morbidity and mortality statistics, and pediatric primary care utilization data in the private care sector (Kumar and Nielsen, 2014). The secondary data were used to facilitate a better integration and understanding of the primary data collected from sources such as published Barbados Census Data, Ministry of Health statistics and available morbidity data from other sources.

An analysis and a discussion on all the available data were conducted to develop a comprehensive utilization and resources inventory (Kumar and Nielsen, 2014).
Data were stored in a password-protected Microsoft Access database and Microsoft Excel was used for generation of tables and graphs. The study being an Operational Research study, ethical approval was deemed not necessary.

Utilization of the available resources and health care provisions were assessed as follows.

Total available professional manpower hours $(\mathrm{AH})$ was calculated using the following formula:

$$
\mathrm{AH}=\mathrm{P} \times \mathrm{WD} \times \mathrm{WH} \times \mathrm{EF}
$$

where $\mathrm{P}$ is the number of full time equivalent persons available for professional duties. MOHs/ SPHNs were counted as 0.5 owing to the fact that they have administrative duties assigned to them, which takes up nearly half of their daily work hours. WD = working days a week = five days; $\mathrm{WH}=$ daily work hours $=8-1 \mathrm{~h}$ for breaks and lunch $=7 \mathrm{~h}$; and $\mathrm{EF}=$ effective work time factor $=0.85$. The proportion of working time actually spent at work after subtracting $15 \%$ for six weeks' vacation and provisions for two weeks of nonvacation leave.

\section{Results}

Table 1 shows the selected demography and data on the pediatric primary health care providers in Barbados. Pediatric services are available at all of the polyclinics and satellite health centers. These include the Well Baby/Child Clinics, which is the only service dedicated to child health. These clinics are managed by the public health nurses and the services include routine follow-up for growth and development assessment and immunization of children under five. Each of the polyclinics and the satellite centers has daily GP clinics, where children of all ages are attended to by the GPs. Although nutritionist's services are available at all of the eight polyclinics but one, the service is not dedicated for children. Other services include dental and eye care services that serve all ages. Rehabilitative services such as physiotherapy, occupational therapy and speech therapy are available for all ages three and a half days a week at two polyclinics. Children who need more specialized rehabilitative services are referred to a centralized children's development center. A quantitative measure of the available health care services at the polyclinics is shown in Table 2. 
Table 2 Service availability and utilization in primary health care setup of the public sector (all polyclinics) in Barbados, 2012

\begin{tabular}{lc}
\hline Service & $\begin{array}{c}\text { Availability numbers } \\
\text { of clinics }{ }^{\text {a }} \text { per week }\end{array}$ \\
\hline $\begin{array}{l}\text { Service dedicated to child health } \\
\quad \text { Well Baby or Child Clinics }\end{array}$ & 16 \\
Services common to all clients & \\
$\quad$ (including pediatric services) & \\
$\quad$ General practice clinics & 240 \\
Nutritional clinics & 28 \\
Ophthalmology clinic & 5 \\
Dental clinic & 5 \\
Mental health clinics & 5 \\
STI clinic & 2 \\
Rehabilitative services & 1.5 \\
$\quad$ (physio/occupational/speech & \\
therapy) &
\end{tabular}

STI = sexually transmitted infection.

a A clinic is one health care professional for a full workday.

None of the polyclinics has any dedicated follow-up clinics for children with chronic diseases. There is no pediatric/specialist service of any kind (except the basic nutritional, dental and eye services mentioned above) available at any of the polyclinics. Where a specialist consultation is necessary, patients are referred to the pediatric department at the publicly funded Queen Elizabeth Hospital (QEH), the only tertiary care institution in Barbados.

There is provision for home visits at all of the polyclinics; however, the interviews show that it is the staffs' perception that most of the polyclinics are unable to provide even half of the desired home visits for newborns. All of the polyclinics have a public pharmacy for dispensing medications prescribed by the physicians from the polyclinics free of any charges. None of the polyclinics has laboratory support for routine investigations, although there is a public health laboratory attached to one of the centrally located polyclinics for testing of stool samples for food-borne diseases and for the respiratory diseases outbreaks. Whenever an investigation is necessary for a patient attending the polyclinics, then sample is collected and sent to the laboratory attached to QEH.

In 2012, there was a total of 161094 visits from children and adults to the polyclinics in Barbados and 62934 of these visits were from children $<16$ years of age (Table 1 ). This translates into 89.7 visits/1000 children/month [(62 934 visits/year/ 58455 children $<16) \times 1000 / 12$ months]. Of the total number of visits to the polyclinics, 26959 were from children less than five years of age to the Well Child Clinic for immunization and for growth and development monitoring, of which 2167 were from children less than one year old. This clinic is managed by the public health nurses and does not require physician consultation. Of the remaining 134135 visits to the polyclinics that were made for the purpose of consultation with the physicians, there were 21408 (16\%) visits to the GP units from children under five years of age and 14567 (11\%) in the age group 5-15 years. In addition, there were 7014 children younger than five years of age $(5.2 \%)$ attending the Well Child Clinics who also needed additional consultations with physicians at the GP clinic. Therefore, annually, 42989 [21 408+14567+ 7014] (32.1\%) consultations with physicians at the polyclinics were from children $<16$ years (Table 1 ). It is equivalent to a utilization of 827 consultations/week.

The interviews showed that need for additional professional manpower was the most commonly felt need by the polyclinics' staffs. Currently, there are $49 \mathrm{GP} /$ physicians evenly distributed among the eight polyclinics (Table 1), including eight $\mathrm{MOH}$ who spend less than half of their daily work hours in service. The 49 physicians are equivalent to $31.6 \%$ of doctors providing primary care to children in Barbados. All of the physicians have MBBS (the basic degree in medical sciences) degree. None of these physicians has postgraduate degree in pediatrics and only few have postgraduate degree in family medicine (general practice equivalent) specialty. There are 71 public health nurses and 52 staff nurses, once again evenly distributed among the eight polyclinics. Staff nurses have the basic degree in nursing, whereas the public health nurses have an additional diploma, having undergone a year of training in public health. A total of 11 of the public health nurses, designated as SPHNs, devote over half of their daily work hours to administrative work and the remaining for the nursing care.

Table 3 shows the professional manpower resources available for consultations at the polyclinics and its utilization.

The interviews showed that need for additional continuous professional development activities (CPDA) and opportunities for further 
Table 3 Professional manpower resources availability and utilizations at the primary health care settings of the public sector (polyclinics) in Barbados, 2012

\begin{tabular}{|c|c|c|c|c|}
\hline \multirow[b]{2}{*}{ All polyclinics } & \multicolumn{2}{|c|}{ Resources } & \multicolumn{2}{|l|}{ Utilizations } \\
\hline & Staff ${ }^{a}$ & $\begin{array}{l}\text { Total available hours for } \\
\text { clinical service per week }\end{array}$ & $\begin{array}{l}\text { Consultations } \\
\text { per week }\end{array}$ & $\begin{array}{l}\text { Time per } \\
\text { consultation }\end{array}$ \\
\hline $\begin{array}{l}\text { Physicians available for clinical } \\
\text { services }^{b}\end{array}$ & 45 & 1339 & 2714 & $29 \mathrm{~min}$ \\
\hline $\begin{array}{l}\text { Public health nurses available for } \\
\text { clinical services }^{c}\end{array}$ & 114 & 2980 & 3616 & \\
\hline Nutritionist & 7 & 208 & 218 & \\
\hline
\end{tabular}

${ }^{a}$ Full time equivalents serving both children and adults.

${ }^{b}$ In all, 41 physicians in clinical positions and eight in administrative positions allocated $50 \%$ clinical work.

Including 518 well children consultations per week attending the Well Child Clinic, which is managed almost entirely by the public health nurses.

Table 4 Annual visits among the children utilizing the primary care services at the polyclinics in Barbados, 2012

\begin{tabular}{|c|c|c|c|c|c|c|}
\hline \multirow{2}{*}{$\begin{array}{l}\text { Polyclinic visits } \\
\text { New visits for the year }\end{array}$} & \multicolumn{2}{|l|}{$<5$ year } & \multicolumn{2}{|c|}{ 5-15 years } & \multicolumn{2}{|c|}{ All children } \\
\hline & 3386 & $15.8 \%$ & 556 & $3.8 \%$ & 3942 & $11.0 \%$ \\
\hline First visits for the year & 6890 & $32.2 \%$ & 3810 & $26.2 \%$ & 10700 & $29.7 \%$ \\
\hline Repeat visits for the year & 11132 & $52.0 \%$ & 10201 & $70.0 \%$ & 21333 & $59.3 \%$ \\
\hline Total visits & 21408 & & 14562 & & 35970 & \\
\hline
\end{tabular}

${ }^{a}$ New Well Baby Clinic visits by children younger than one year is $2167(10.1 \%)$.

professional development was the second most commonly felt need by the polyclinics' staffs. All of the polyclinics have some form of CPDA. However, there is no protected time or structured program for CPDA for either the nurses or the physicians. Both the physicians and the nurses spend $<5 \%$ of their work time for CPDA. The third most common item from the interviews was that guidelines are lacking. Guidelines for the management of common illnesses that are specifically written for children and available at hands for use in the routine care of children are lacking. Likewise, there are no locally written procedural manuals that are available at hand for any of the common health services/interventions provided at these polyclinics.

Table 4 shows the number of repeat visits to the polyclinics in 2012 . Overall, $11 \%$ of children who visited any one of the polyclinics during the given year were new patients who had never visited the polyclinics in the past and $89 \%$ of visits were by children who have had previous visits to that facility (first visit and repeat visits for the year). An overall $59 \%$ of the children who visited the facility during 2012 have had one or more previous visits (repeat visits) during 2012. An overall 15.8\% of the children younger than five years who visited the polyclinics were new and $3.8 \%$ of children aged five or more were new patients.

The frequency of the common diagnoses among children who visited the GP clinic at the polyclinics is shown in Figure 1. Upper respiratory tract was the most common over all diagnoses (31\% among children younger than five years and $20 \%$ among children aged five or more) for children visiting the polyclinics. The second most common (18\% among children younger than five years and $8 \%$ among children aged five or more) reason for visit to the polyclinics was for issue of health certificates for healthy children going back to day care centers, preschool and schools.

\section{Discussion}

Barbados has a pluralistic health care system, whereby people have a choice to utilize the health 


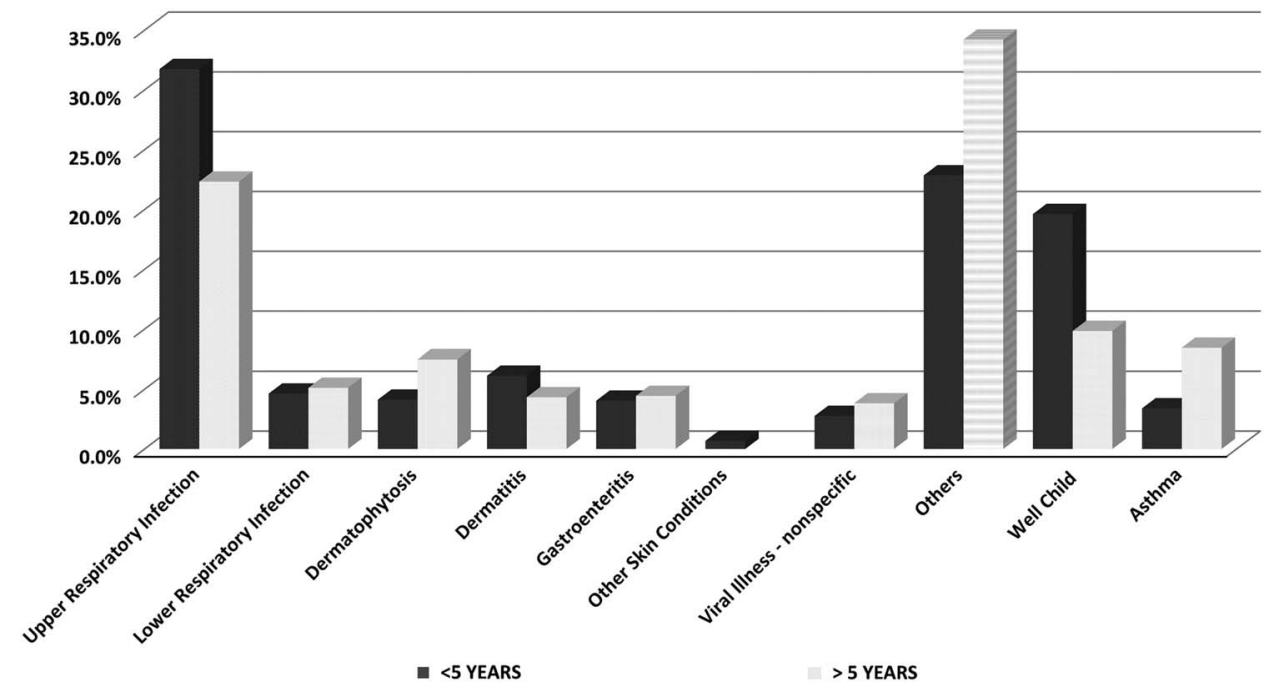

Figure 1 Diagnosis for the children seen in the GP unit of the polyclinics in Barbados, 2011

services in the public sector free of charges at the point of delivery or in the private sector at a fee that is out of pocket or through a number of the health care insurance schemes available. The public health care system has historically been the largest provider of primary health care in this country (PAHO, 2013). The primary health care in the public sector is delivered through a chain of eight primary health care centers called the polyclinics. There is almost a parallel system of primary health care for children being provided by the physicians in the private medical sector. The private sector includes GP's (physicians with MBBS degree and a further degree in general practice or family medicine), pediatricians (physicians with MBBS degree and a further degree in pediatrics) and the physicians with just the basic MBBS degree who are addressed as GP's as well (PAHO, 2013). For an island with an area of $431 \mathrm{~km}^{2}$, geographically evenly spread eight polyclinics and two satellite health care centers are considered to provide fairly easy accessibility.

Professional workforce resources, especially in terms of physicians and nurses, were the most commonly felt need by the health care workers interviewed at the polyclinics. It must be pointed out that it was difficult to ascertain the professional workforce resource need in this setting. Lack of dedicated pediatric services and/or dedicated pediatric service providers (doctors/nurses) make it very difficult to have a clear idea of the resource need for the primary health care for children. The density of doctors in Barbados is 1.81/1000 inhabitants (CIA, 2014), which is lower than the 2.5 physicians/1000 for United States and the OECD average of 3.1/1000 (OECD, 2014). However, with 144 full time physicians in general practice (ie, 0.50 physicians in general practice/1000 inhabitants), the percentage of doctors in general practice is $27.6 \%$ in Barbados, which is close to the OECD average of $26.9 \%$ (OECD, 2014).

What is obvious from this study is the total lack of qualified pediatricians' service at the primary care level in this country. Barbados has on average 3500 live born deliveries annually. It is well accepted that all infants should be consulted with a pediatrician at least once in the first year of life (Banister, 1970). This alone would translate into at least 3500 pediatrician visits in the primary care settings annually in this country.

Childrens' utilization of health services as most papers define it, visits per 1000 inhabitants/month, is 167 for Japan with a socialized system (Ishida et al., 2012), the same figure as reported in the United States (Dovey et al., 2003). In Sweden, which also has a socialized system, the reported number is 192 visits/month/1000 (Ferro and Kristiansson, 2011). Based on the published literature, the round figure of 185 visits/month/ 1000 children could be considered as a reasonable 
'standard' demand (Dovey et al., 2003; Ferro and Kristiansson, 2011; Ishida et al., 2012). Applied to Barbados with a population of 58455 under 16 years, this country should have a monthly demand of 10814 visits from children. Therefore, with the annual visits to the polyclinics from children at 5245 visits/month (89.7 visits/1000 children/ month), it would seem that the polyclinics serve $48.5 \%$ of the estimated demand for the primary health among children.

A study of seven European countries found that the average consultation time varies by country. For Germany it was 7.6 and in Switzerland 15.6 $\mathrm{min} /$ consultation. The mean length for the seven countries is $11.4 \mathrm{~min}$ (Deveugele et al., 2002). Dividing the number of doctors' hours available per week in Barbados with the number of consultations per week is equal to $29 \mathrm{~min} /$ consultation in average (Table 3). Assuming that a patient consultation takes in average $15 \mathrm{~min}$ (a conservative estimate re. above figures), it indicates that there is unused capacity available in Barbados, that is, a potential to increase the number of consultations with $48 \%$. Seemingly, it is not a capacity problem that the primary care setup in the public sector of Barbados is faced with. In fact, the figures point to the contrary with a possibility of $48 \%$ increase in the present capacity to provide primary care to children and adults in the public sector. However, we do not have data to assess whether it reflects a capacity limitation owing to inefficient operations.

Based on the interpretation of data from the year 2012, it is noted that there were 3386 new visits to the polyclinics from children less than five years and of these 2167 were visits to the Well Baby Clinic by children less than one year. Given the annual number of births is 3500 (CIA, 2014), the given number of annual new visits to the Well Baby Clinic would account for $61.9 \%$ of the infants delivered in 2012.

The most important and compulsory reason for visits during the first year of life is for immunizations. Based on the aforementioned data, it would be reasonable to assume that a significant number of children utilize the free immunization service at the polyclinics and this may have accounted for the high number of annual new visits. The needed repeat vaccinations might also explain the $52 \%$ repeat visits during the same year in children less than five years. The aforementioned assumption is further substantiated by the fact that annually there were 26959 (Table 1) visits to the under five Well Child Clinic. It translates roughly into seven immunization visits and one extra Well Baby visit at nine months for growth monitoring. The numbers of births in Barbados has been 3500/year and also for the four years before 2012. So an estimate of the demand for visits to the Well Baby Clinic will be 28000 visits/year [ $(5$ visits $_{1}$ year +1 visits $_{2}$ year +1 visits $_{3}$ year +1 visits $_{4}$ year) $\times 3500$ ]. That the immunization is primarily done in the polyclinics can also be seen from the fact that $79 \%$ of all vaccine doses are distributed to the polyclinics (Kumar and Nielsen, 2014).

Therefore, when it comes to the question of seeing a physician for the children's illnesses, it seems likely that the parents choose the health care providers in the private sector, which may be perceived to provide better facility/expertise/ accessibility (Johnston et al., 2012). This could explain why only half of the total expected numbers of visits from children take place at the polyclinics. However, it is well established that immunization is one of the most cost-effective interventions in health care. Therefore, from a public health perspective, it is advantageous for the government to ensure high coverage of vaccination in this country, without having to bear the burden of entire health care cost (PAHO, 2013; WHO, 2014). Inadvertently, it ensures a healthy private-public partnership in the health sector.

The relatively high proportion $(70 \%)$ of repeat visitors among children in the age group 5-15 years to the polyclinics (Table 4) is likely multifactorial. One explanation could be repeated visits from a subset of the childhood population with chronic disorders/multiple diseases/low-income families. It is often the marginalized and disadvantaged population that bears the brunt of this group of diseases such as sickle-cell disease and asthma. Respiratory illnesses account for $30 \%$ of the diagnosis (Figure 1). Polyclinics may have been utilized as the major care provider for this vulnerable population. Once again, from a public health perspective, this is a pivotal role played by the public primary health care sector.

Regardless of the explanation, the high number of repeat visits is a strong argument for the need of having a dedicated follow-up clinic at each of the polyclinics. This would ensure the continuity of 
care in the management of these chronic conditions and making it more effective, holistic and cost-effective at the community level. In this regard, having locally developed rational and relevant guidelines and standard procedure manuals would ensure uniform standards of care to these children. All such improvements could be achieved at no additional cost of care, as these children are already utilizing the health care services at the polyclinics, and would be economically beneficial in the long term.

The major limitation of this study is the inadequate rigor of the assessment of the resources and the health care utilization parameters. This was mainly owing to the lack of availability of comprehensive records and statistics from the polyclinics because all recording is manually done. Lack of dedicated services and service providers for children made the assessment and interpretation of data very difficult. Although, not a limitation directly linked to the design or methods of this study, lack of published data on optimal professional resources such as the number of physicians, pediatricians and nursing resources was a limitation. Few published data for children of the needs and optimum number of primary care visits was also a major limitation for making a useful and meaningful comparison in this study.

In summary, the polyclinics, which serve as the primary health care units in the public sector, fulfill nearly half of the total primary health care demand for children in this country. More significantly, it provides for almost all of the immunization services for the children. This is extremely useful from a public health perspective because it ensures the high immunization coverage that is reported. The polyclinics also seem to provide the medical care for the marginalized and vulnerable group of children with chronic diseases and therefore play a pivotal role in promoting equitable access of health care provisions in this country. The existing resources, if used optimally, would reduce the long consultation time observed in this setting, and thereby increase the capacity considerably.

There is a need for periodic and more focused audit of the primary health care services in order to make the services client friendly, more efficient and economical. Finally, there is a need for CPDA to ensure evidence-based practice of medicine in this setup.

Primary Health Care Research \& Development 2016; 17: 157-165

\section{Acknowledgment}

The authors would like to thank S. Petersen and P. Singh who reviewed the document during its development.

\section{Financial Support}

This study was supported by the Ministry of health, Government of Barbados.

\section{Conflicts of Interest}

None.

\section{References}

Banister, P. 1970: Too many children or too many pediatricians. Canadian Medical Association Journal 103, 1312.

CIA. 2014: The World Factbook. Retrieved 17 July 2014 from https://www.cia.gov/library/publications/the-world-factbook/ geos/bb.html

Deveugele, M., Derese, A., Brink-Muinen, A.V.D., Bensing, J. and Maeseneer, J.D. 2002: Consultation length in general practice: cross sectional study in six European countries. BMJ 325, 472.

Dovey, S., Weitzman, M., Fryer, G., Green, L., Yawn, B., Lanier, D. and Phillips, R. 2003: The ecology of medical care for children in the United States. Pediatrics 111, 1024-29.

Ferro, A. and Kristiansson, P.M.D. 2011: Ecology of medical care in a publicly funded health care system: a registry study in Sweden. Scandinavian Journal of Primary Health Care 29, 187-92.

Institute of Medicine (IOM). 2012. Primary care and public health: exploring integration to improve population health. Washington, DC: The National Academies Press.

Ishida, Y., Ohde, S., Takahashi, O., Deshpande, G.A., Shimbo, T., Hinohara, S. and Fukui, T. 2012: Factors affecting health care utilization for children in Japan. Pediatrics 129, e113-19.

Johnston, R., Crooks, V.A., Snyder, J., Fraser, H., Labonté, R. and Adams, K. 2012. An overview of Barbados' medical tourism industry. Burnaby, Canada: Simon Fraser University.

Kumar, A. and Nielsen, A.L. 2014: Strengthening primary health care in pediatrics. Bridgetown: Ministry of Health.

OECD. 2014: OECD StatExtracts. Retrieved 17 July 2014 from http://stats.oecd.org/index.aspx?DataSetCode=HEALTH_ STAT

PAHO. 2013: Health in the Americas - Barbados. Retrieved 17 July 2014 from http://www.paho.org/saludenlasamericas/index. php?id=23\&option=com_content\&Itemid=0\&lang=en 
Parchman, M.L. and Culler, S. 1994: Primary care physicians and avoidable hospitalizations. The Journal of Family Practice 39, 123-28.

Shi, L. 1994: Primary care, specialty care, and life chances. International Journal of Health Services 24, 431-58.

Starfield, B. 1994: Is primary care essential? Lancet 344, 1129-133.
UNICEF. 2013: Barbados Statistics. Retrieved 17 July 2014 from http://www.unicef.org/infobycountry/barbados_statis tics.html

United Nations Development Program (UNDP). 2014: International human development indicators. UNDP. Retrieved 17 July 2014 from http://hdr.undp.org/en/countries

WHO. 2014: Barbados. WHO, Geneva. Retrieved 17 July 2014 from http://www.who.int/countries/brb/en/ 